\title{
Separation Anxiety and its Relation to Parental Attachment Styles among Children
}

\author{
Sawzan Sadaqa Basyouni* \\ Mental Health and Psychological Counseling, College of Education, Umm al-Qura University \\ *Corresponding author: sawzanbasyouni@yahoo.com
}

\begin{abstract}
The present study aimed at identifying the relationship between parental attachment styles and separation anxiety in the light of the gender of children. Therefore, the scales of separation anxiety and parental attachment were prepared and applied to a sample of 300 students from the upper grades in the primary stage in Jeddah. Results showed statistically significant correlation coefficients between parental attachment styles (anaclitic attachment, anxious attachment, and preoccupied attachment) and separation anxiety (depressive symptoms associated with parental separation anxiety, social concerns, fear of child-mother separation, general anxiety, and total degree of parental separation anxiety). There were no statistically significant differences in anxious attachment and depressive symptoms associated with parental separation anxiety and fear of parent's departure from the house.
\end{abstract}

Keywords: separation anxiety, parental attachment, primary stag

Cite This Article: Sawzan S. Basyouni, "Separation Anxiety and its Relation to Parental Attachment Styles among Children.” American Journal of Educational Research, vol. 6, no. 7 (2018): 967-976. doi: 10.12691/education-6-7-12.

\section{Introduction}

The environment tremendously affects the child's personality formation and its future style. In general, the child's relationships with one's parents, brothers, sisters, and relatives define one's personality style and attitudes towards the others and the things. Psychologists, such as Freud and Bowlby, agree on the significance of family role and strong impact on the child's socialization, personality formation, as well as social and psychological development. That is, parents' attention and love form the child's development [1].

The tripartite relation (father-mother- child) is the source of the child's proper development. In other words, the parents shall provide the child with attention, care, control, and education. They also share life responsibilities. Their love for the child is fundamental to one's psychological development. Children tend to be close to other individuals whom they appreciate. This behavioral style is called attachment.

Attachment is essential for growth because the child's attachment to parents affects one's future and relationships with the others. Bowlby indicated that the emotional ties between the child and the parents help formulate a mental model on one's self and relationships with others [2].

Cherry [3] argues that child's attachment comprises various forms, such as: the child's desire to be close to the individual he is attached to, reliance on this individual to feel assured and secure when encountering difficult and frightening circumstances, reliance on this individual as a source of searching for information and exploration, as well as feeling anxious if the source of attachment is not existent.
Merhag [4] and Al-Shapoan [5] define the factors that affect the formation of attachment behavior, as follows:

1. Factors related to the individual: age, personality, and mood characteristics.

2. Factors related to parents: physical closiness to the child and identifying the child's psychological and biological needs.

3. Factors related to maturity and the environment: development of attachment selective behavior necessitates that the child is capable of distinguishing the individuals and that $\mathrm{s} / \mathrm{he}$ has social responses.

Shehada and Al-Asemy [6] identify the following attachment styles:

1. Secure (positive) attachment: Positive towards the self and the others.

The individual counts on the others to explore the new surrounding environment, endeavors to interact with them, and $\mathrm{s} / \mathrm{he}$ is disturbed due to their departure.

2. Insecure- avoidant attachment: Positive towards the self and negative towards the other.

The individual seeks a great deal of independence; avoids relations because $\mathrm{s} /$ he feels self-sufficient; believes that $\mathrm{s} / \mathrm{he}$ is not sentimental; and prefers suppression, withdrawal, and denial; and searches for arguments to be away from the partner, if any.

3. Anxious (negative) attachment: negative towards the self and positive towards the other.

The individual seeks to attain a high degree of intimacy and approval as well as expects a total response from the partner on whom s/he extensively counts.

Characteristics of attachment behavior $[7,8]$

1. Search for closeness: The individual's attempt to be close to the attachment figures.

2. Secure base: presence of attachment figures provides the individual with security and relief. 
3. Separation rejection: the individual's attempt to refuse separation from the attachment figures.

4. It sets basis for the individual's future relationships and defines his/ her attitudes towards the self, others, and life in general.

Attachment generates the interest of many theories of psychology. For example, in the psychoanalysis theory, Erikson believes that attachment emergence is based on the child's ability to form it, namely the parents will satisfy the child's needs. Such confidence is the basis of attachment behavior [9].

The behavioral theory explains attachment according to the concept of reducing the stimulant. The mother, for example, satisfies the child's hunger (primary stimulant). Hence, she becomes a secondary stimulant because her presence is associated with the child's feeling of comfort and satiety [10].

The classical attachment theory of "Bowlby, 1969" is a beneficial framework for understanding the parent-child attachment relationship. Secure attachment is believed to be a sentimental tie which is usually encouraged by the parents' sensitivity to their children's needs and feelings. It also provides the child with a close emotional relationship and a secure base essential for exploring his/her environments [11].

Parental attachment is a system controlling a stimulant that enhances safety and security in both breastfeeding and childhood based on the child's relationship with the parents who are available and responsive in times of danger, violence, and new situations that are continuous and necessitate attachment to parents or others [11].

Accordingly, the author assumes that attachment behavior is not some simple or random behaviors directed towards any individual within the environment, but it is a directed behavior that arises as a result of complex conscious and unconscious processes and moves towards specific people in the individual's environment. Consequently, the individual feels relieved and stable due to the presence of those people.

Based on this importance of attachment, several studies have been conducted on attachment styles and their relationships to some variables. For instance, Matsuoka et al. [12] aimed at investigating attachment styles among adolescents according to gender variable. Results indicated that level of secure and anxious attachment among females is higher than that of males.

Karairmak and Duran [13] aimed at identifying gender differences in attachment styles among adolescents. Results revealed differences in attachment Styles between males and females, in favor of females in the secure style and in favor of males in the avoidant one.

Abu Ghazal and Jaradat [14] investigated the relationship between adult attachment styles and self-esteem as well as loneliness, the most common attachment style, as well as the differences between attachment styles due to social gender. Results showed that the anxious and secure attachment styles correlated with self-esteem and loneliness. Furthermore, the most common attachment style was the secure one and there were no differences between the attachment styles in both genders.

Abu Nimer [15] aimed at identifying the relationship between the prevailing attachment styles and self-disclosure level among adolescent students. Results revealed that the prevailing attachment styles were the secure, avoidant, and anxious one, respectively. In addition, there were differences in avoidant and secure styles due to gender in favor of the females and in the anxious one in favor of the males.

Youssef and Ibrahim [16] examined the relationship between attachment styles and cognitive methods (meditation - impulsiveness) and (reliability - autonomy) among university students. Results showed that participants preferred secure attachment to the avoidant and anxious ones. They also preferred cognitive style more than impulsiveness. Moreover, there was a relationship between attachment (secure-avoidant) and cognitive method (reliability - autonomy).

Abu Ghazal and Floah [17] investigated the most common attachment style and the most frequent method used to resolve social problems among adolescent students, exploring whether there were significant differences between attachment styles and methods of resolving social problems according to gender and age group. This study also identified the relationship between attachment styles and social problems solving among adolescent students. Results showed that the most common attachment style was the secure one and that the rational solution was frequently used to solve social problems. In addition, there were differences related to gender in anxious attachment style in favor of the males.

Ghafel et al. [18] identified attachment styles in light of gender. Results demonstrated that adolescents had a high level of attachment. Additionally, there was a difference between the averages of males and females on attachment styles.

Warekart and Tanus [19] identified attachment styles and their relation to future anxiety among orphanages' children in Amman. Results indicated a correlation between anxious as well as avoidant attachment and future anxiety, while there was no correlation between secure attachment and future anxiety.

Accordingly, it is obvious that most literature handled attachment, in general, while one study tackled parental attachment This shows the difference between the present study and the other studies. It also shows the importance of attachment, in general, and parental attachment, in particular. Parental attachment is fundamental to the individual's future personality as well as social security and passion.

According to Bani Moustafa \& Al-Sharefain [20], the Diagnostic and Statistical Manual of Mental Disorders- $4^{\text {th }}$ ed. (DSM-IV) indicates the most prominent disorders resulting from children's attachment are as follows:

- The child is extremely concerned about separation from attachment figure as well as excessively afraid for his/her safety.

- The child's anxiety and fear of loneliness in case of the attachment figure's absence.

- Frequent nightmares resulting from separation anxiety and being away from the attachment figure.

- Suffering from physical symptoms, such as headache, nausea, abdominal recurrent pain, and anorexia.

Hence, there is a relationship between attachment styles and separation anxiety as an important variable in the psychological development of the individual. The degree of separation anxiety is defined according to the style and 
nature of the child's attachment to the caregiver. Consequently, the inverse relationship between the degrees of attachment and separation anxiety is apparent [21].

The child should have emotional stability to cope up with the difficult circumstances due to the deprivation of father or mother and to encounter life hardships effectively. The less anxious and tense the child is, the more compatible with the self and the others she/he becomes [22].

Consequently, deprivation may significantly impact the child's psyche, behavior, and personality. She/he feels anxious and tense due to fear of losing a parent as a result of the hard situation encountered. Thus, the child's trust in the self and others is strongly affected.

Separation anxiety, as defined in DSM-IV, is a psychiatric disorder prevalent among children. It is a mental state in which the patient suffers from excessive concern about separation from home or the individuals with whom she/he has a strong emotional relationship, such as parents, grandparents, or siblings [23].

Separation anxiety is the state of uneasiness, confusion, and worries which results from the constant fear of losing close persons. That is, children are only concerned about losing a close one [24].

Authors identified several and interrelated causes of separation anxiety, including genetics, family and learning, as well as psychological and social factors [25]. [26]:

Separation anxiety disorders comprise several styles

- Behavioral disorders: Children prefer to grasp the interest of others.

- Emotional disorders: multiple fears, such as fear of darkness, imagining predatory animals chasing them, and symptoms of depression.

- Physical disorders: diseases and physical disorders, such as headaches, stomachache, nausea, and vomiting.

- School disturbances: lack of concentration, laziness, and frequent absence.

Forbes [27] claims that the child's separation anxiety involves the following stages:

- Protest and search: The child protests and cries due to separation from the father or the mother.

- Despair: The child realizes parent's absence and his/her inability to meet him or her.

- Separation: The child removes all emotions and feelings towards the absent individual.

Salman and Hussein [28] argued that many theories addressed separation anxiety, such as:

- Psychoanalysis theory: Freud believed that this anxiety is the preliminary one or birth shock because the baby separates from mother's body.

- Ethological perspective: Ethologists consider it a natural human characteristic, such as anxiety or fear of strangers.

- Separation and distinction theory by Margaret Mahler: It emphasizes the importance of the relationship between mother and child from birth to the age of two months when children get into autism and see their mother as a factor that satisfies their basic needs.

- Attachment and correlation theory by Bolby: It handles the relationship between the child and parents, as well as its impact on the child's mental, physical, and emotional health.
The author adopted the attachment and correlation theory by Bolby because it elaborately handles the concept, sources, components, and the possibility of measuring separation anxiety through its fields. Furthermore, it is accurate, concise, and comprehensive.

According to Hisham [26], the following approaches and methods can be used to treat separation anxiety:

- Behavioral cognitive therapy: Exposing children to fearful situations related to separation in order to prevent anxiety response and to develop a cognitive strategy and relaxation exercises to enable children to control anxiety.

- Family therapy: Convincing parents that it is a psychological disorder not a type of delicacy and its treatment requires understanding rather than strictness.

- Environmental therapy: It is adopted with cases associated with specific environmental situations, such as concern about going to school. It requires coordination between parents and teachers.

- Individual Psychotherapy: Understanding the unconscious meaning of the symptoms experienced by the child as well as reinforcing the child's personality to cope up with separation anxiety situations through psychological sessions at the psychiatric clinic.

- Medical treatment: The doctor gives the child some psychological drugs that reduce the fear of separation.

According to the statistics, anxiety disorders are one of the most common psychological diseases that currently affect young people. They influence (5-25\%) of children worldwide. Such disease can reach (50\%) according to the records of psychiatric hospitals. Researches indicate that (1.4\%) of children's case may get worse. Various researches addressed it because it is one of the diseases which all individuals may catch [28,29].

Therefore, several studies have been conducted to clarify the relationship between separation anxiety and many variables. For example, Salih and Al-Sumairi [30] investigated the relationship between separation anxiety and self-confidence among parentless children in Gaza Governorates. Results revealed a negative correlation between separation anxiety and self-confidence among the parentless children and there were differences in the overall degree of separation anxiety scale in favor of females. Furthermore, there were significant differences between both genders in the total degree of selfconfidence scale in favor of males.

Ora et al. [31] investigated the relationship between separation anxiety among adolescents in junior high school and parents as well as parental attachment styles and the relationship with self-concept. Results showed no differences between separation anxiety for parents and adolescents.

Al-Qureshi [29] developed a scale to measure separation anxiety among the children who lost their parents in terrorist and military acts. Results demonstrated that participants suffered from separation anxiety that affected the females more than the males.

Nasser [32] studied separation anxiety among kindergarten children in Muthanna Governorate as well as differences in the variables of the study according to gender (males and females). Results showed high indicators of separation anxiety among kindergarten children. In addition, there 
were statistically significant differences in separation anxiety according to gender (males and females) in favor of the females.

Furthermore, some studies tackled the relationship between separation anxiety and family disorders, such as:

Hijazi [33] showed that the child, who lost one or both parents, feels deprived and deficient. Thus, she/he suffers from anxiety, tension, lack of self-confidence, low selfconcept, and lack of adaptation, as well as psychological and social incompatibility. Not only actual separation but also threat creates anxiety. The greater the threat is, the greater the attachment becomes.

Hajaj [34] examined the psychological impact of father's absence due to divorce or separation on children aged (9-11). Results showed differences between students (living with both parents) and (parentless) students in anxiety degree in favor of the parentless ones.

Several studies have handled the close relationship between the child's attachment to the important person in his life and the excessive anxiety about separation. For example, Weems et al. [35] examined the relationship between attachment and anxiety in a sample of adolescent and adult students. Results indicated that all school and university students with insecure attachment had a high degree of separation anxiety. However, individuals with secure attachment style showed a low degree of anxiety.

Orion [36] examined the relationship between the manifestations of attachment and separation among children. Results indicated positive correlations between the degree of attachment among children and the development of autonomy and self-control feelings.

Dallaire and Weinraub [37] explored the predictive ability of attachment to mothers, and its relationship to separation anxiety. Results showed that children with insecure attachment showed a higher degree of separation anxiety, whereas those with secure attachment showed a lower degree. Moreover, children with avoidant attachment had the highest degree. In addition, separation anxiety was the highest when attachment got more secure.

Vijaya et al. [38] examined the relationship between attachment styles in two groups; one suffered from separation anxiety and the other suffered from panic disorder. Results showed a strong correlation between attachment styles and separation anxiety compared to the relationship between attachment styles and panic disorder. Furthermore, the participants with insecure attachment had a high degree of separation anxiety.

Bani Moustafa \& Al-Sharefain [20] studied the relationship between separation anxiety and attachment styles to surrogate mothers in the light of gender, age, and period of residence in the village. Results indicated that the level of separation anxiety among children was moderate, the most prominent style was secure attachment, and correlation coefficients between these variables were generally moderate. In addition, differences in the level of separation anxiety were attributed to age. Moreover, the difference in the degree of avoidant style was attributed to residence duration in the village.

To conclude, it is obvious that various studies handled the relationship between attachment and the level of separation anxiety in the light of several psychological and social variables.
It is important to know that the deeper attachment to the important individual and attachment figure is, the higher separation anxiety becomes. The child normally experiences temporary separation or permanent separation. It is expected that separation cases cause no problems or disorders if the attachment style is secure. However, the author claims that Arabic studies and researches have not addressed the relationship between separation anxiety and parental attachment. Therefore, the present study seeks to identify separation anxiety and its relationship to parental attachment styles among primary school students.

\subsection{Statement of the Problem}

The problem of the present study is defined in the negative impacts of the child's fear of separation from parents and the individuals with whom she/he has positive relationships. Accordingly, it is necessary to identify the relationship between parental attachment and separation anxiety. To address this problem, the study attempts to answer the following major question:

What is the relationship between separation anxiety and parental attachment styles among children?

It is further subdivided into the following minor questions:

1. What is the relationship between separation anxiety (among male and female children) and parental attachment styles?

2. Does parental attachment style differ according to gender (male and female)?

3. Does separation anxiety differ according to gender (male and female)?

4. What is the effect of the interaction between gender and attachment style on separation anxiety among children?

\subsection{Objectives}

The study attempts to identify the following aspects:

1. The relationship between separation anxiety (among male and female children) and parental attachment styles.

2. Differences in parental attachment style according to gender (male and female).

3. Differences in separation anxiety according to gender (male and female).

4. The effect of the interaction between gender and attachment style on separation anxiety among children.

\subsection{Hypotheses}

1. There is a statistically significant correlation between parental attachment styles and separation anxiety among male and female children (separately).

2. There are statistically significant differences between the averages of children on the scale of parental attachment styles according to the gender (males and females).

3. There are statistically significant differences between the scores of children on the scale of separation anxiety according to gender (males and females). 
4. There is an effect of the interaction between gender (males/females) and parental attachment styles on separation anxiety.

\subsection{Significance}

It is a significant study because:

- It provides parents and educators with suggestions that alleviate separation anxiety and help them properly treat the child in order to mitigate anxiety impact on the child's behavior and personality in the future.

- It identifies children who have insecure attachment styles and offers them solutions.

- It enables parents, teachers, and mentors to take the actions which create parental attachment styles that alleviate children's separation anxiety.

- It offers a tool that measures attachment styles and diagnoses various problems experienced by children.

- It enables specialists of psychological counseling and mental hygiene to create guidance and therapeutic programs based on attachment theory.

- It stimulates future studies that tackle separation anxiety in post-primary stage.

\subsection{Definition of Terms}

\subsubsection{Separation Anxiety}

It is procedurally defined as the concerns that the child experiences early in life due to separation from one or both parents. Subsequently, she/he has clinical problems, depression, fear of change, loss feeling, and worry about abnormal situations. The level of separation anxiety is defined based on the total degree the student gets on the separation anxiety scale (fear of separation from mother, social anxiety, generalized anxiety, and depression symptoms associated with separation anxiety) prepared by the author.

\subsubsection{Attachment}

Procedurally, it is an emotional attachment and a type of emotional as well as social behaviors that arise between the child and the parents. Consequently, she/he adopts some actions gained from the attachment to the individual who protects and cares about him/her. It is defined according to the overall degree the student obtains on the attachment scale (including anxious attachment, anaclitic attachment, and preoccupied attachment) prepared by the author.

\subsubsection{Parental Attachment}

It is procedurally defined as student's tendency to approach and attach to the parents who provide him/her with reassurance, confidence, and needs. It is the degree the student gets on the parental attachment scale.

\subsection{Sampling}

The sample comprised (300) students (147 males and 153 females) in the three upper grades of the primary stage, as shown in Table 1.
Table 1. Distribution of the participants according to gender and grade

\begin{tabular}{|c|c|c|c|}
\hline Grade & Male Students & Female Students & Total \\
\hline Fourth & 50 & 50 & 100 \\
\hline Fifth & 50 & 50 & 100 \\
\hline Sixth & 47 & 53 & 100 \\
\hline
\end{tabular}

In addition, the tools of study were applied to (65) students to obtain the psychometric characteristics of the scales. The participants are aged (9.5) to (12) years. They are enrolled in the primary schools 81,41 , and 176 located in the middle and north of Jeddah.

\subsection{Tools}

\subsubsection{Scales of Parental Attachment Styles (by the author)}

Upon reviewing some attachment scales adapted for children and adults [39] and Yarmouk scale of adults' attachment styles [14], the author designed a scale for children attachment styles to measure the attachment styles between the child and the parents. This scale consists of (20) items to be answered according to fivepoint Likert scale. The items are divided into three styles, as follows:

1. Anaclitic attachment

It reflects the individual's trust and reliance on the others (parents) and the simplicity of making close relationships with them.

\section{Anxious attachment}

It reflects the extent to which the individual negatively perceives himself/herself and positively perceives the others. As a result, he/she feels anxious.

\section{Preoccupied attachment}

It reflects the extent to which the individual is content, calm, and delighted in case of closeness and contact with others.

\subsection{Statistical Processing}

\subsubsection{Validity}

A. Evaluators’ Validity

Ten faculty members at the Department of Psychology, Psychological Counseling and Mental Hygiene at Umm Al-Qura University, King Abdulaziz University and Women College in Riyadh evaluated the scale validity. There were no observations on the items or their relevance to the aspects they address. In addition, factor analysis was applied according to the basic components method and rotation was conducted using Varimax Rotation. Results showed (3) factors, as shown in Table 2.

Table 2. Results of factor analysis of attachment styles' scale

\begin{tabular}{|c|c|c|c|}
\hline Factor & Latent Root & Variance Rate & Accumulative Variance \\
\hline 1 & 2.92 & 11.69 & 27.21 \\
\hline 2 & 1.67 & 6.87 & 33.38 \\
\hline 3 & 1.35 & 5.19 & 39.29 \\
\hline
\end{tabular}


Items of the first factor (i.e. 1, 3, 7, 17, 18, and 19) refer to anxious attachment and indicate the individual's negative feelings towards the self and positive feelings towards the others. Items of the second factor (i.e. 2, 6, 8, 10,13 , and 16) refer to anaclitic attachment and reveal the individual's trust and reliance on the others as well as the possibility of making close relationships with them. Items of the third factor (i.e. 4, 5, 9, 11, 12, 14, 15, and 20) refer to preoccupied attachment and reveal to what extent the individual feels content, calm, and delighted in case of closeness and attachment with parents.

B. Internal consistency

The consistency of a sample of (65) students of (3) upper primary grades in Jeddah was estimated using the internal consistency method for the item of the attachment style. All the items have statistically significant consistency coefficients at (0.01), as shown in Table 3.

Consistency coefficients between the dimensions and total degree of the scale were estimated, as follows: Anxious (0.84), anaclitic (0.74), and preoccupied (0.80). All coefficients seem high and satisfactory. They also indicate high validity.

c. Reliability

Reliability of the scale was estimated using split-half and alpha coefficient after checking by Spearman-Brown equation for each dimension of the scale. Values of alpha coefficient were (0.90-0.83) and split-half coefficients were (0.64-0.76). All coefficients were high and satisfactory.

\subsubsection{Second: Separation Anxiety Scale for Children: (by the author)}

The author reviewed various scales concerning separation anxiety, such as separation anxiety scale [40] Spence Adolescents and Children's Anxiety Scale (translated by Abd-Alaziz Thabet).

The scale consists of (40) items to be answered by Likert two-point scale (Yes) or (No). the items are divided into 4 factors: fear of separation from mother, social concerns, generalized anxiety, and depressive symptoms associated with separation anxiety in addition to the total degree of parental separation anxiety.

\subsubsection{Validity}

The above-mentioned ten evaluators examined and approved the scale validity.

\subsubsection{Internal Consistency}

The author applied the scale to the same sample. After estimating correlation coefficients خب the items degrees and the total degree of the scale, it was detected that there were statistically significant internal consistency coefficients at (0.01), as shown in Table 4.

Table 3. Consistency coefficients of attachment scale and its dimensions

\begin{tabular}{|c|c|c|c|c|c|c|c|c|}
\hline \multicolumn{2}{|c|}{ Dimension } & $\begin{array}{r}\text { consistency } \\
\text { coefficient }\end{array}$ & \multicolumn{2}{|c|}{ Dimension } & $\begin{array}{c}\text { consistency } \\
\text { coefficient }\end{array}$ & \multicolumn{2}{|c|}{ Dimension } & $\begin{array}{r}\text { consistency } \\
\text { coefficient }\end{array}$ \\
\hline \multirow{6}{*}{$\begin{array}{l}\text { Anxious } \\
\text { attachment }\end{array}$} & 1 & 0.534 & \multirow{6}{*}{$\begin{array}{l}\text { Anaclitic } \\
\text { attachment }\end{array}$} & 2 & 0.495 & \multirow{6}{*}{$\begin{array}{c}\text { Preoccupied } \\
\text { attachment }\end{array}$} & 4 & 0.645 \\
\hline & 3 & 0.541 & & 6 & 0.683 & & 5 & 0.708 \\
\hline & 7 & 0.613 & & 8 & 0.518 & & 9 & 0.541 \\
\hline & 17 & 0.709 & & 10 & 0.621 & & 11 & 0.546 \\
\hline & 19 & 0.625 & & 16 & 0.589 & & 12 & 0.589 \\
\hline & 18 & 0.549 & & 13 & 0.642 & & 14 & 0.642 \\
\hline & \multirow{3}{*}{$\begin{array}{c}\text { Total } \\
\text { Degree }\end{array}$} & \multirow{3}{*}{0.84} & \multirow{3}{*}{\multicolumn{2}{|c|}{ Total Degree }} & \multirow{3}{*}{0.074} & & 15 & 0.721 \\
\hline & & & & & & & 20 & 0.642 \\
\hline & & & & & & & Total Degree & 0.80 \\
\hline
\end{tabular}

Table 4. Internal consistency correlations of the items of parental separation anxiety scale

\begin{tabular}{|c|c|c|c|c|c|}
\hline No. & correlation coefficients & No. & correlation coefficients & No. & correlation coefficients \\
\hline 1 & $* * 0.4915$ & 16 & $* * 0.6467$ & 30 & $* * 0.4249$ \\
\hline 2 & $* * 0.6005$ & 17 & $* * 0.5080$ & 31 & $* * 0.5386$ \\
\hline 3 & $* * 0.4853$ & 18 & $* * 0.5125$ & 32 & 0.1458 \\
\hline 4 & $* * 0.5151$ & 19 & $* * 0.6287$ & 33 & $* * 0.5209$ \\
\hline 5 & $* * 0.5116$ & 20 & $* * 0.5290$ & 34 & $* * 0.6130$ \\
\hline 6 & $* * 0.4483$ & 21 & $* * 0.6472$ & 35 & $* * 0.6959$ \\
\hline 8 & $* * 0.6281$ & 22 & $* * 0.4337$ & & \\
\hline 9 & $* * 0.6778$ & 23 & $* * 0.7383$ & 36 & $* * 0.7499$ \\
\hline 10 & $* * 0.5996$ & 24 & $* * 0.4633$ & 37 & $* * 0.7335$ \\
\hline 11 & $* * 0.8060$ & 25 & $* * 0.7582$ & 38 & $* * 0.5594$ \\
\hline 12 & $* * 0.5993$ & 26 & $* * 0.7742$ & 39 & $* * 0.6133$ \\
\hline 13 & $* * 0.6319$ & 27 & $* * 0.7970$ & 40 & $* * 0.2808$ \\
\hline 14 & $* * 0.4079$ & 28 & $* * 0.6061$ & & \\
\hline 15 & $* * 0.2765$ & 29 & $* * 0.6078$ & & \\
\hline
\end{tabular}




\subsubsection{Reliability}

Reliability of parental separation anxiety scale was verified by applying it to another sample to make sure that separation anxiety scale was reliable. The sample consisted of (60) students. Cronbach's Alpha equation was estimated for all items. Reliability coefficient was evaluated using the re-test method within a six- week interval. Reliability coefficient was statistically significant at (0.01), with a value of (0.817). Based on the results of reliability and validity coefficients, it is obvious that the scale has high coefficients of reliability and validity. Thus, they can be adopted as indicators of the scale validity and reliability.

\section{Results and Interpretation}

\subsection{The $\mathbf{1}^{\text {st }}$ hypothesis}

There is a statistically significant correlation between parental attachment styles (i.e. anaclitic, anxious, and preoccupied) and parental separation anxiety (depressive symptoms associated with parental separation anxiety, social concerns, child's fear of maternal separation, generalized anxiety, and total degree of parental separation anxiety) among male and female students, except for the two dimensions associated with depressive symptoms and the child's fear of parents' absence from home in case of parental attachment style (i.e. anxious), as shown in Table 5.

This result (Table 5) is consistent with the results of Orion [36], Dallaire and Weinraub [37], Karairmak and Duran [13], Vijaya et al. [38], and Bani Moustafa \& AlSharefain [20].

The relationship between the degree of the child's parental attachment and the sense of separation is determined in the light of the emotional relationship the child has with parents as a result of achieving biological and psychological satisfaction as well as the emotional pressure that she/he experiences when she/he doesn't get this satisfaction due to parental separation. The discrepancy in correlation coefficients and their significance is determined by the nature of the child's parental attachment, the type of emotional relationships she/he has with them, and the degree of dependence on them to reach satisfaction. The preoccupied child depends on parents to satisfy his/her needs more than the other two types (anaclitic and anxious). The anaclitic child depends on parents to satisfy his/her needs more than the anxious child.

The correlation between parental attachment and the experience of separation is specified in the light of parental support. The child's closeness to the support figure reassures him/her, while separation creates anxiety, discomfort, and insecurity. The degree of anxiety, discomfort, and insecurity varies in the light of the child's relationship with the parents and consequences of separation from them.

The insignificant relationship between anxious attachment and depressive symptoms associated with separation anxiety among males is determined according to their serious attempts to overcome anxiety symptoms. It is also determined in the light of the actual ability of male children, compared to females, to cope up with life problems. Furthermore, the insignificant relationship between the child's fear of leaving parents and anxious attachment among males is determined in the light of male children's courage to overcome the situation. They adhere to such trait to conform to the others' expectations. In consistence with other studies, it is also determined according to high self-concept and early distinction among the males compared to the females.

Abu Ghazal and Jaradat [14] revealed a positive relationship between secure attachment and self-esteem because the individuals with secure attachment may have higher social skills and social self-efficacy. They also highly trust their relationships with the others. In addition, they are satisfied with such relationships which facilitate social interaction and give a positive impression to others.

\subsection{The $2^{\text {nd }}$ Hypothesis}

There are statistically significant differences between males and females with regard to parental attachment styles at the level of (0.01) on anaclitic and preoccupied attachments, in favor of the females. There are also statistically significant differences at the level of (0.05) for the anxious attachment, in favor of the males, as shown in Table 6.

Table 5. Correlation coefficients between parental attachment styles and parental separation anxiety among male and female children

\begin{tabular}{|c|c|c|c|c|c|c|}
\hline & \multicolumn{2}{|c|}{ Anaclitic } & \multicolumn{2}{|c|}{ Anxious } & \multicolumn{2}{|c|}{ Preoccupied } \\
\hline & Males & Females & Males & Females & Males & Females \\
\hline depressive symptoms associated with separation anxiety & 0.468 & 0.583 & $* 0.149$ & 0.163 & 0.676 & 0.798 \\
\hline social concerns & 0.645 & 0.661 & 0.202 & 0.315 & 0.547 & 0.697 \\
\hline child's fear of maternal separation & 0.419 & 0.398 & *0.093 & 0.165 & 0.719 & 0.856 \\
\hline general anxiety & 0.571 & 0.649 & 0.317 & 0.430 & 0.436 & 0.519 \\
\hline total degree of separation anxiety & 0.472 & 0.491 & 0.236 & 0.311 & 0.419 & 0.527 \\
\hline
\end{tabular}

*All correlation coefficients are statistically significant except the starred ones.

Table 6. Male and female differences in the averages of attachment styles

\begin{tabular}{|c|c|c|c|c|c|}
\hline \multirow{2}{*}{ Attachment Style } & \multicolumn{2}{|c|}{ Males } & \multicolumn{2}{|c|}{ Females } \\
\cline { 2 - 5 } & means & standard deviation & means & standard deviation \\
\hline Anaclitic & 21.32 & 5.63 & 24.17 & 4.17 & $* 5.0300$ \\
\hline Anxious & 19.26 & 5.44 & 17.78 & 28 & $* 2.4322$ \\
\hline Preoccupied & 22.48 & 4.87 & 25.44 & 4.71 \\
\hline
\end{tabular}

*Significant differences at the level of $(0.01)$

**Significant differences at the level of (0.05). 
This result is consistent with the results of Matsuoka et al. [12], Abu Nimer [15], Abu Ghazal and Floah [17], and Ghafel et al. [18].

The gender differences are interpreted, as follows:

It is interpreted in the light of the results of other studies, reporting that the individuals' behavior changes towards the others according to gender. These differences are consistent with the perspective on gender-based stereotyping and socialization. The females are educated to develop the emotional attachment, while the males pursue the development of an independent identity and maintain personal freedom. Furthermore, these differences can be explained in the light of the discrepancy of warmth and positiveness that parents offer to their children as well as how they are offered according to gender.

These differences may also be related to gender's attachment behavior and autonomy development. Although females and males learn to serve themselves at the same age, the females may adhere to attachment behavior more than males; they need more physical closeness with parents. The discrepancy also occurs owing to the behavior expected in the community. Some behaviors are accepted from females, while males must assert their physical and emotional independence.

\subsection{The $3^{\text {rd }}$ Hypothesis}

There are statistically significant differences at the level of (0.01) among the participants with regard to the degrees of separation anxiety and its dimensions.
These differences are in favor of females who are more sensitive to separation from parents. This result agrees with the results of the studies which handle mental disorders and confirm that the females are more likely to have emotional disorders than males, as shown in Table 7.

The results (Table 7) are consistent with Matsuoka et al. [12], Salih and Al-Sumairi [30], Al-Qureshi [29], and Nasser [32].

The Differences are interpreted as follows:

The gender differences occur as a result of differences with regard to the way of response to the situations that cause anxiety. Males generally tend to respond more effectively, while females tend to respond to emotional feelings associated with separation anxiety through exaggerating them. These differences are attributed to the biological characteristics which contribute to the female's formation of a strong emotional tie towards parents. Life pressures highly affect the females who greatly respond to them. Thus, they suffer from separation anxiety because of exposure to life problems and the inability to face them effectively.

On the other hand, these results match those of Matsuoka et al. [12] and Abu Ghazal and Jaradat [14] concerning the absence of significant differences between males and females on the dimension of the child's fear of separation from mother and leaving home. This result is interpreted in the light of the fact that male and female children do not differ in their need for parents to satisfy their needs and desires to obtain warmth, tenderness, and love. Consequently, their feelings to parents are similar although females' degrees are higher than the males'.

Table 7. Differences between the means of separation anxiety degrees and its different dimensions

\begin{tabular}{|c|c|c|c|c|c|}
\hline \multirow{2}{*}{ Variables } & \multicolumn{2}{|c|}{ Males $=140$} & \multicolumn{2}{|c|}{ Females $=160$} & \multirow{2}{*}{$\mathrm{T}$} \\
\hline & means & standard deviation & means & standard deviation & \\
\hline Fear of separation from mother & 4.22 & 6.42 & 6.58 & 5.78 & 3.25 \\
\hline Social concerns & 5.99 & 4.78 & 6.81 & 5.91 & 3.53 \\
\hline Depressive symptoms associated with separation from parents & 5.31 & 5.63 & 7.42 & 4.86 & 3.52 \\
\hline Generalized anxiety & 7.82 & 5.64 & 9.82 & 4.59 & 6.48 \\
\hline Total degree of separation anxiety & 23.40 & 7.11 & 25.86 & 6.33 & 3.20 \\
\hline
\end{tabular}

Table 8. Results of two-variance analysis of parental attachment styles and gender regarding separation anxiety and its dimensions

\begin{tabular}{|c|c|c|c|c|c|c|}
\hline $\begin{array}{l}\text { separation anxiety and } \\
\text { its dimensions }\end{array}$ & Source of Variance & $\begin{array}{l}\text { Total sum of } \\
\text { Squares }\end{array}$ & Freedom Degree & $\begin{array}{l}\text { Squares } \\
\text { Average }\end{array}$ & F-Value & $\begin{array}{l}\text { Significance } \\
\text { Level }\end{array}$ \\
\hline \multirow{4}{*}{$\begin{array}{l}\text { Depressive symptoms } \\
\text { associated with } \\
\text { separation from parents }\end{array}$} & Gender & 46.42 & 1 & 46.42 & 7.23 & 0.01 \\
\hline & Attachment Styles & 70.36 & 2 & 35.18 & 5.48 & 0.01 \\
\hline & Gender * Attachment Styles & 54.06 & 2 & 27.03 & 4.21 & 0.05 \\
\hline & Within groups & 1964.52 & 306 & 6.42 & & \\
\hline \multirow{4}{*}{$\begin{array}{l}\text { Fear of separation from } \\
\text { mother }\end{array}$} & Gender & 66.60 & 1 & 66.60 & 9.46 & 0.01 \\
\hline & Attachment Styles & 89.13 & 2 & 44.56 & 6.33 & 0.01 \\
\hline & Gender * Attachment Styles & 77.02 & 2 & 38.51 & 5.47 & 0.01 \\
\hline & Within groups & 2154.24 & 306 & 7.04 & & \\
\hline \multirow{4}{*}{ Social concerns } & Gender & 11.14 & 1 & 11.14 & 2.55 & Insignificant \\
\hline & Attachment Styles & 32.25 & 2 & 16.13 & 3.69 & 0.05 \\
\hline & Gender * Attachment Styles & 29.28 & 2 & 14.64 & 3.35 & 0.05 \\
\hline & Within groups & 1337.22 & 306 & 4.37 & & \\
\hline \multirow{4}{*}{ Generalized anxiety } & Gender & 26.49 & 1 & 26.49 & 4.56 & 0.05 \\
\hline & Attachment Styles & 62.52 & 2 & 31.26 & 5.38 & 0.01 \\
\hline & Gender * Attachment Styles & 56.24 & 2 & 28.12 & 4.84 & 0.01 \\
\hline & Within groups & & 306 & 5.81 & & \\
\hline \multirow{4}{*}{$\begin{array}{l}\text { Total degree of } \\
\text { separation anxiety }\end{array}$} & Gender & 135.84 & 1 & 135.84 & 8.63 & 0.01 \\
\hline & Attachment Styles & 180.07 & 2 & 90.03 & 5.72 & 0.01 \\
\hline & Gender * Attachment Styles & 201.79 & 2 & 100.89 & 6.41 & 0.01 \\
\hline & Within groups & 4816.44 & 306 & 15.74 & & \\
\hline
\end{tabular}


Table 9. Mean differences between the groups of attachment styles concerning separation anxiety and its dimensions using Bonferroni method

\begin{tabular}{|c|c|c|c|c|c|c|}
\hline Separation anxiety and its dimensions & Attachment styles & $N(1)=137$ & $N(2)=89$ & $N(3)=86$ & \multicolumn{2}{|c|}{ Critical Value } \\
\hline $\begin{array}{l}\text { Depressive Symptoms } \\
\text { G1 }=6.19 \\
\text { G2 }=4.71 \\
\text { G3 }=8.65\end{array}$ & $\begin{array}{c}\text { Anaclitic (1) } \\
\text { Anxious (2) } \\
\text { Preoccupied (3) } \\
\end{array}$ & - & $\begin{array}{c}1.48 \\
-\end{array}$ & $\begin{array}{c}2.46 \\
3.94 \\
- \\
\end{array}$ & 0.8734 & 1.0764 \\
\hline $\begin{array}{l}\text { Fear of Separation from Mother } \\
\text { G1 }=10.19 \\
\text { G2 }=8.95 \\
\text { G3 }=12.94\end{array}$ & $\begin{array}{l}(1) \\
(2) \\
(3)\end{array}$ & - & $\begin{array}{c}1.24 \\
-\end{array}$ & $\begin{array}{c}2.75 \\
3.99 \\
-\end{array}$ & 0.9146 & 1.1271 \\
\hline $\begin{array}{l}\text { Social Concerns } \\
\text { G1 }=6.05 \\
\text { G2 }=5.46 \\
\text { G3 }=7.77\end{array}$ & $\begin{array}{l}(1) \\
(2) \\
(3)\end{array}$ & - & $\begin{array}{c}* 0.59 \\
-\end{array}$ & $\begin{array}{c}1.72 \\
2.31 \\
- \\
\end{array}$ & 0.7206 & 0.8880 \\
\hline $\begin{array}{l}\text { Generalized Anxiety } \\
\text { G1 }=5.22 \\
\text { G2 }=5.11 \\
\text { G3 }=7.62\end{array}$ & $\begin{array}{l}(1) \\
(2) \\
(3)\end{array}$ & - & $\begin{array}{c}* 0.11 \\
-\end{array}$ & $\begin{array}{c}2.40 \\
2.51 \\
- \\
\end{array}$ & 0.8309 & 1.0239 \\
\hline $\begin{array}{l}\text { Total Degree } \\
\mathrm{G} 1=26.70 \\
\mathrm{G} 2=24.03 \\
\mathrm{G} 3=29.36\end{array}$ & $\begin{array}{l}(1) \\
(2) \\
(3)\end{array}$ & - & $\begin{array}{c}2.67 \\
-\end{array}$ & $\begin{array}{c}2.66 \\
5.33 \\
-\end{array}$ & 1.3676 & 1.6854 \\
\hline
\end{tabular}

\subsection{The $4^{\text {th }}$ Hypothesis}

The results of two-variance analysis of parental attachment styles and gender regarding the degrees of separation anxiety's dimensions among children are as follows:

There are statistically significant differences between the groups regarding separation anxiety among children due to:

1. Differences in parental attachment styles.

2. Gender difference, except for the dimension regarding fear of separation from the mother because the differences are not gender-based.

3. Interaction between parental attachment styles and gender.

Table 8 illustrates the results.

Examination of the differences between the groups of different parental attachment styles regarding the degrees of separation anxiety and its dimensions using Bonferroni method [41] indicated significant differences between the different groups of parental attachment styles. These differences are in favor of the preoccupied attachment compared to the other two groups (anaclitic and anxious attachment). They are in in favor of the group of anaclitic attachment when compared to the group of anxious attachment. Table 9 illustrates these results.

This result (Table 9) agrees with the results of Youssef and Ibrahim [16], Muhammad [11], Abu Ghazal and Floah [17], and Warekart and Tanus [19].

The results of the $4^{\text {th }}$ hypothesis are interpreted based on the fact that difference in parental attachment styles and the type of the emotional relationship among the children and their parents may make a difference regarding the children's feelings towards the parents, the biological and psychological needs offered to them, and subsequent difference regarding separation feelings and sense of reattachment.

Accordingly, preoccupied attachment style is more influenced by separation than the other two styles. The anaclitic style is more influenced by separation than anxious attachment. The anxious attachment is less influenced by separation than the other styles because the child's relationship with parents is troubled as well as the needs offered to him/her are less than those of the other styles. This indicates that those with preoccupied and anaclitic attachments are more sensitive and afraid of separation from parents because of the feelings related to the inability to satisfy their needs easily.

\section{Recommendations}

- Developing counseling programs to mitigate separation anxiety.

- Holding seminars and delivering lectures to parents to increase their awareness of the most important methods to deal with the children who suffer from separation anxiety.

- Increasing communication methods between home and school in order to detect the causes behind the children's behavioral problems.

- Conducting studies on the nature of and social factors to this psychological and social phenomenon.

\section{References}

[1] Abd-Alrazek, E. (2005). Realization of the psychological absence of the father and the behavioral problems among Children. A paper presented at the $12^{\text {th }}$ Annual Conference, Psychological Counseling Center, Faculty of Education, Ain Shams University.

[2] Benjamin, G. (2004). Kaplan\& Salons comprehensive tickets. Behavioral oral science clinical psychiatry.

[3] Cherry, K. (2005). Attachment styles. Available at http.7/Psyschology. About.com.

[4] Merhag, R. (2001). Our children from birth to adolescence. Beirut: Academia International.

[5] Al-Shapoan, D. (2006). Psychological security and its relation to psychological loneliness: A field study on a sample of the fourth and sixth grade students at the schools of Damascus Governorate (MA. Thesis). College of Education, Damascus University. 
[6] Shehada, A. \& Al-Asemy, R. (2016). Attachment to peers and its relation to emotional empathy in a sample of master candidates at the College of Education, Damascus University. Journal of Psychological and Educational Sciences, 3(1), 170-195.

[7] Browne, C. J. \& Shlosberg, E. (2006). Attachment theory, ageing and dementia: A review of the literature. Aging \& Mental Health, 10(2), 142-154.

[8] Hassan, H. (2006). Attachment to parents and peers and its relation to self-efficacy and symptoms of depression in adolescence. Journal of Faculty of Education, Tanta University, 2 (35), 703-770.

[9] Badir, K. (2010). Psychological principles of child growth $\left(6^{\text {th }}\right.$ ed.), Amman: Dar Al- Maseera.

[10] Abu Assad, A. (2011). Counseling psychology. Amman: Dar AlMaseera.

[11] Muhammad, S. (2014). Parental meta-emotion and parental attachment style among children. Psychological Counseling Journal, 37, 287 -251.

[12] Matsuoka, N., Hiramura, H., Shikai, N., Kishida, Y. \& Hitamura, T. (2006). Adolescents attachment style and early experiences: A gender difference. Archives of Women's Mental Health, 9, 23-29.

[13] Karairmak, Ö. \& Duran, N. (2008). Gender differences in attachment styles regarding conflict handling behaviors among Turkish late adolescents. International Journal for the Advancement of Counselling, 30(4), 220-234.

[14] Abu Ghazal, M. \& Jaradat, A. (2009). Styles of adults' attachment and their relation to self-esteem and loneliness. The Jordanian Journal of Educational Sciences, 5 (1), 45-57.

[15] Abu Nimer, M. (2011). Attachment styles and their relation to self-disclosure among adolescent students in Upper Galilee (MA. thesis). Yarmouk University, Irbid, Jordan.

[16] Youssef, H. \& Ibrahim, R. (2013). Attachment styles and their relation to cognitive methods (meditation - impulsiveness) and (reliability - independence) among university students. Journal of Humanities, (58), 51-62.

[17] Abu Ghazal, M. \& Floah, A. (2014). Attachment styles and resolving social problems among adolescent students according to gender and age. The Jordanian Journal of Educational Sciences, 10 (3), 351-368.

[18] Ghafel, G., Kasem, Z. \& Ghaid, Z. (2017). Attachment styles among adolescents in middle schools in Qadisiyah Governorate. Department of Educational and Psychological Sciences, College of Education, University of Al-Qadisiyah.

[19] Warekart, H. \& Tanus, A. (2018). Attachment styles and their relation to future anxiety among the children in orphanages. Journal of the Islamic University for Educational and Psychological Studies, 26(2), 416-439.

[20] Bani Moustafa, M. \& Al-Sharefain, A. (2012). Separation anxiety and attachment styles to surrogate mothers among orphan and deprived children in light of some variables. Journal of Ismailia Faculty of Education, Suez Canal University, 12 (22), 85-126.

[21] Kassem, N. (2004). Recent trends in the studies and researches of attachment as a manifestation of personality development. Al-Nafs Al-Zakia Journal, (4).

[22] Al-Hayan, F. \& Al-Mashan, A. (2015). Differences in the concepts of self and personality among the children of prisoners as well as martyrs and their peers in other families. Palestinian Studies Journal, 15(2).

[23] Separation Anxiety Disorder (2015). Alnafs Almotmaena Newspaper, (110). Available at: elazayem.com/public/upload/mental.../1509442171.
[24] Yemina, M. (2015). The problem of attachment for the child. University of Algeria, retrieved from www.univ-eloued.dz/rers/images/pdf/M122015066.pdf.

[25] Steele, H., \& Steele, M. (2005). Understanding and resolving emotional conflict: The london parent-child project. In K. E. Grossmann, K. Grossmann, \& E. Waters (Eds.), Attachment from infancy to adulthood: The major longitudinal studies (pp. 137164). New York, NY, US: Guilford Publications.

[26] Hisham, S. (2016). Children and the problem of separation anxiety: causes and solutions. Hia Magazine. Available at https://www.hiamag.com.

[27] Forbes, G. (2000). Gender role typing and attachment to parents and peers. The Journal of Social Psychology, 140(2), 258-260.

[28] Salman, S. \& Hussein, N. (2017). Separation anxiety and its relation to working memory among primary stage students. Journal of College of Education for Women, University of Baghdad, 28 (2), 722 -741.

[29] Al-Qureshi, A. (2016). Separation anxiety among parentless children due to terrorist and military acts. College of Education Journal, Mustansiriya University, Iraq, 107-128.

[30] Salih, A. \& Al-Sumairi, N. (2009). Separation anxiety and its relation to self-confidence among parentless children in Gaza Governorate. A paper presented at Towards a Better Investment of Educational and Psychological Sciences in the Light of Age Challenges. College of Education, Damascus University, Damascus.

[31] Ora, P., Paul, M. \& Meital, Y. (2015). Is separation anxiety in adolescents and parents related to parental differentiation of self. British Journal of Guidance \& Counselling, 43(4), 413-428.

[32] Nasser, N. (2017), Separation anxiety among kindergartners, Uruk Journal, 10 (2), 481-506.

[33] Hijazi, M. (2004). Mental health: A dynamic and supplementary perspective of growth at home and school. Beirut: The Arab Cultural Center.

[34] Hajaj, E. (2007). The psychological impact of father's absence on primary stage students (MA. thesis). Faculty of Education, Ain Shams University.

[35] Weems, G., Berman, S., Silverman, W., \& Rodrigues, E. (2002). The relation between anxiety sensitivity and attachment style in adolescence and early adulthood. Journal of Psychopathology and Behavioral Assessment, 24(3), 159-168.

[36] Orion, J. (2002). Infant Attachment and separation: The foundations for social/emotional growth. NAMTA Journal, 27(1), 31-43.

[37] Dallaire, D., \& Weinraub, M. (2005). Predicting children's separation anxiety at age 6: The contributions of infant-mother attachment security, maternal sensitivity. Attachment \& Human Development, 7(4):393-408.

[38] Vijaya, M., Derrick, S., Claire, M., \& Renate, W. (2009) Adult attachment styles in panic disorder with and without comorbid adult separation anxiety disorder. Journal of Psychiatry, 43(2), 167-172.

[39] Collins, N. \& Read, S. (1990). Adult attachment, working models, and relationship quality in dating couples. Personality and Social Psychology, 85 (4), 644.

[40] Awad, A. \& Abdelhameed, M. (1990). Separation anxiety among children- a factorial study. A paper presented at the $6^{\text {th }}$ Conference of Psychology, vol.1, the Egyptian Society for Egyptian Studies, Cairo.

[41] Myers, J. (1979). Fundamentals of experimental design ( $3^{\text {rd }}$ ed.), Boston, MA.: Allyn and Bacon. 